Trab. Ling. Aplic., Campinas, 44(2): 201-214, Jul./Dez. 2005

\title{
A QUESTÃO DE ASPECTO NOS TEMPOS VERBAIS EM INGLÊS
}

\author{
LINDA GENTRY EL-DASH \\ (Unicamp)
}

\begin{abstract}
RESUMO
Os tempos verbais em inglês são problemáticos para os aprendizes brasilieros. Este texto enfatiza o que subjaz aos tempos verbais em português e contrasta os resultados obtidos com a importância do aspecto na escolha dos tempos, especialmente os tempos do passado, em inglês. Algumas das implicações pragmáticas dessas diferenças são também discutidas.

Palavras-chave: tempos verbais, aspecto verbal, ensino-aprendizagem de língua.
\end{abstract}

\section{ABSTRACT}

English verb tenses are problematic for Brazilian learners. This text briefly outlines what underlies the verb tenses in Portuguese and contrasts this with the importance of aspect in the choice of tenses, especially the perfect tenses, in English. Some of the pragmatic implications of these differences are also discussed.

Key-words: verbal tenses, verbal aspect, teaching-learning language.

Logo que cheguei ao Brasil, ouvi falar de um certo John Schmitz que escrevia uma tese de doutorado sobre os verbos ser e estar. Já sofria com esses verbos e, sem conhecer John, fiquei impressionada pelo fato de ele ter coragem de refletir publicamente sobre algo tão complicado. Depois, encontrei com ele em um GEL no interior do estado; pareceu-me um homem simples e simpático, mas nunca imaginei que, um dia, ele viria para a Unicamp e seria o meu orientador no programa de doutorado. E nunca deixei de tê-lo como o modelo de uma pessoa que tinha o que para mim era a coragem - ou a audácia - de tentar desvendar os segredos da gramática.

Com o passar dos anos, comecei a me interessar pelos tempos verbais do inglês, porque se, para mim, eram tão naturais, para os alunos, eram um sofrimento. Quando me lembrei do exemplo de John e da sua coragem em atacar os verbos ser e estar, decidi que eu também me arriscaria tentando entender melhor a minha língua, na esperança que pudesse ajudar os outros a entendê-la. Este texto é fruto dessa investigação.

\section{A PROBLEMÁTICA DOS TEMPOS VERBAIS}

A questão do tempo verbal na língua inglesa e o seu uso efetivo no discurso é complicada, porque o que subjaz à escolha de uma ou outra opção é diferente do que 
subjaz ao significado e ao uso dos tempos verbais em português. As orações nas duas línguas têm proposições semelhantes (em geral, expressam que um dado agente (o sujeito) fez alguma coisa sob certas condições temporais ou locais). Essa proposição é o conteúdo semântico / lexical da oração e identifica os referentes no mundo (real ou imaginário). Assim, João comprou uma caneta identifica o fato de que existe uma entidade, João, que se envolveu numa situação de compra de uma caneta. Poderia localizar tal evento em relação a onde aconteceu (por exemplo, na loja X) ou ao instrumento usado (com o seu cartão de crédito) e assim por diante, mas o núcleo consiste na idéia de que uma entidade se envolveu numa situação específica.

\section{TEMPOS VERBAIS EM PORTUGUÊS}

Quando as pessoas falam, elas não se limitam a referentes físicos no mundo. Também relatam quando algo acontece ou aconteceu. Assim, em português, ao enunciar, o falante identifica um ponto de referência temporal para situar o evento no tempo. Afirma que acontece agora (no presente), aconteceu no passado (pretérito do perfeito ou imperfeito), acontecerá no futuro (futuro), aconteceu no passado antes de outro evento (Mais-queperfeito) ou ia acontecer depois de algum evento no passado (futuro do pretérito). O que determina o uso da maioria desses tempos verbais é o momento da situação, quando o evento aconteceu em relação ao momento da fala. Com verbos no presente simples, por exemplo, o evento normalmente se situa no presente (embora também exista o emprego desse tempo para falar de eventos passados a fim de simular mais proximidade ou vivacidade, como também de eventos ainda por acontecer, se já foi definido ou agendado o acontecimento:

Tenho aula amanhã.

Vou para Europa nas férias.

Se não for definido o tempo da ação, usa-se o tempo futuro para fazer referência a situações futuras.

O que fará da sua vida?

Existe uma questão interessante em relação aos tempos verbais com referência ao tempo verbal mais-que-perfeito, que reflete ações antes de outras ações. Freqüentemente substituído pela forma composta tinha + particípio, esse tempo verbal não é de uso freqüente, porque a simples anteposição da frase, a menção de um evento antes da menção de outro, convida a inferir (pelo menos implicitamente) a ordem cronológica.

Ele foi para os Estados Unidos e encontrou com a sua futura esposa. 
Trab.Ling.Aplic., Campinas, 44(2) - Jul./Dez. 2005

É óbvio que a ida antecede o encontro com a mulher. Outras expressões como antes de ou depois de também podem assinalar uma seqüência temporal.

Depois da ida para os Estados Unidos, conheceu a sua futura esposa.

Antes de conhecer a sua futura esposa, ele tinha ido / fora para os Estados Unidos.

Embora o uso do mais-que-perfeito seja útil para deixar mais explícito o aspecto, a presença das outras expressões deixa clara a relação entre os eventos e evita a necessidade do seu uso.

\section{SITUAÇÕES PASSADAS EM PORTUGUÊS}

Entre as situações temporais possíveis, temos a situação passada. Mas, nesse caso, não há uma única forma para fazer referência a esse tempo. Há duas. O falante de português precisa explicitar a maneira pela qual é vista uma situação no passado. Eventos no passado podem ser vistos como eventos "fechados" (com o uso do pretérito do perfeito (João comprou a caneta) ou como tendo um desenvolvimento através do tempo passado, com o imperfeito (João comprava a caneta [quando encontrou com a namorada]). A diferença entre os dois tipos de eventos passados envolve uma questão de aspecto, de como a situação é vista. Eventos passados podem ser vistos como fechados ou, nos termos de Comrie (1976: 25), com "falta de referência explícita à consistência temporal interna da situação", expressos com o tempo verbal pretérito perfeito ou vistos como tendo "referência explícita à estrutura temporal interna da situação, como se fosse olhar a situação de dentro", indicando uma certa repetição ou duração (com o uso do pretérito imperfeito); essa distinção é gramatical em português e não há como fazer referência a situações passadas sem especificar se estão contempladas como sendo eventos fechados ou eventos que tinham uma certa duração. Falar que se fez uma coisa é diferente de falar que se fazia a mesma coisa. São significados diferentes: quando se muda o tempo verbal, muda-se a mensagem.

A distinção entre "fez" e "fazia", entre o pretérito do perfeito e o pretérito imperfeito é obrigatória, mas o tempo de referência é o mesmo. O que muda é o aspecto, a maneira de encarar a situação. Essa distinção entre aspectos diferentes é dominada por todos os falantes nativos de português, mas é muito pouco ensinada na escola. Ela subjaz à maneira de encarar o mundo e todos os acontecimentos passados que existem.

\section{A QUESTÃO DO ASPECTO}

Rafferty (1982) define aspecto como "uma categoria verbal que define a perspectiva a partir de qual o falante olha um estado/evento/atividade.... Em contexto, significados aspectuais não são referenciais, mas relacionais, no sentido de que não necessariamente refletem a duração real e objetiva nem a delimitação de um estado/evento/ação no mundo 
real, mas, pelo contrário, refletem a avaliação do falante sobre a relação de um estado/ evento/ação com outros estados/eventos/ações no discurso" (p. 66). Friedrich (apud Li et al.: 19) apresenta três sistemas ou categorias básicas de aspecto: 1) durativa, continuativa, etc., 2) pontual, completiva, perfetiva, etc., e 3) estativa, "perfect", etc." Li et al. afirmam que a função desses aspectos é essencialmente pragmática: a diferença do perfeito / imperfeito (do segundo sistema aspectual de Friedrich), por exemplo, é a distinção entre figura (ênfase) (expressa com o pretérito do perfeito) e pano de fundo (com o pretérito imperfeito), ao relatar experiências. Essa distinção é importante ao relatar eventos relacionados entre si. É esse o sistema aspectual envolvido na distinção entre pretérito do perfeito e o pretérito imperfeito no português.

Ao mesmo tempo que existem esses usos "gramaticalizados" da distinção entre as situações duradouras/em progressão e as "fechadas", a língua portuguesa também dispõe do recurso de locuções verbais, através das quais consegue dar uma ênfase a aspectos específicos dos eventos. Costa (1997) aponta a importância das perífrases construídas com verbos de ligação e formas nominais (Gerúndio e Particípio) na expressão de Aspecto e Voz; Almeida (1978) coloca que a perífrase verbal tem a função de "melhor caracterizar as nuanças de raciocínio" que se desenvolvem devido à "insuficiência do quadro das configurações verbais" para assim "adaptar-se à grandeza das expressões das idéias" orelha do livro) $)^{1}$. Nos seguintes pares de orações, a referência é a mesma, mas a segunda coloca mais ênfase na maneira como se vê a estruturação interna do tempo: a casa queimava / estava queimando quando chegaram os bombeiros; visitava / costumava visitar a minha avó nas férias.

\section{ASPECTO EM INGLÊS}

A questão de aspecto é diferente em inglês. Nessa língua, o sistema aspectual é primordial, mas o sistema de imperfeitividade/ perfeitividade (segundo sistema de Friedrich é irrelevante. Entretanto, o primeiro sistema aspectual, que envolve a expressão obrigatória do aspecto de progressão ou duração de eventos, é crucial, como também o é o terceiro sistema aspectual do perfect com a função de focar ou trazer o estado da situação contemplada (state of affairs) para dentro da situação atual, de fazer um comentário sobre situações em relação a um tempo de referência.

Ao falar inglês, o falante terá que incluir essa informação aspectual se for relevante, uma vez que a distinção entre os aspectos é gramatical. O quadro abaixo mostra os aspectos relevantes para o inglês.

\footnotetext{
${ }^{1}$ Nosso foco é o sistema verbal (tempo e aspecto) do inglês, para fins de aprendizagem dessa língua e, por isso, não citamos a literatura sobre o tema na língua portuguesa.
} 


\begin{tabular}{|c|c|}
\hline Existência & $\begin{array}{c}\text { Sistema 3: Estados delimitados / resultantes de } \\
\text { ações }\end{array}$ \\
\hline $\begin{array}{c}\text { Sistema 1: Ações em progresso / } \\
\text { temporários }\end{array}$ & $\begin{array}{c}\text { Sistema } 2+\text { Sistema } 3: \text { Progressão de estados } \\
\text { ou } \\
\text { Ações temporários delimitados }\end{array}$ \\
\hline
\end{tabular}

\section{AÇÃO vs ESTADO}

Esse gráfico nos lembra da importância dos conceitos de ação e estado, que é a chave para a compreensão dos verbos em inglês (El-Dash, 2005). O traço de estado ou ação é inerente ao significado lexical dos verbos e influencia o seu comportamento gramatical. Estados são, por definição, relativamente permanentes, sem início, meio ou fim. E relatam situações categóricas: um estado ou é ou não é.

I don't have a dog.

She is a teacher.

Mary knows the answer.

Um estado é como um fato que se nega ou se afirma. Nesses exemplos, ou se possui um cachorro ou não se possui; se é professora ou não se é; sabe-se a resposta ou não se sabe. São situações vistas como dicotômicas, de existência ou falta de existência, sem vacilações. Se a existência de um estado não está bem definida, muda-se o verbo. Assim, temos

Do you know French?

No, but I'm learning it.

Em português, percebe-se a natureza não categórica de verbos semelhantes com exemplos como o seguinte (informal), que sugere um conhecimento parcial via uso da forma contínua do verbo:

Você sabe a matéria da prova?

Ahh, eu 'tou sabendo, mas essa parte de $\mathrm{X}, . .$. não estou entendendo.

Ações, por outro lado, envolvem algum tipo de mudança de estado, de desenvolvimento: run, walk, etc. e tendem a ter um início, meio e fim: eat, fall, etc. Durante a ação de correr, ocorrem mudanças (de localização, de movimentos dos membros, etc.); quando se come ou cai, há um início, um meio e um fim. 
John ran to the store.

I eat a lot of cheese.

The boy fell out of the tree.

A questão de estado é irrelevante em português. Em inglês, entretanto, existe uma gama de verbos descrevendo situações vistas como duradouras, sem mudanças, que descrevem situações categóricas. Esses incluem os verbos de sensações (os cinco sentidos de see, hear, feel, smell, e taste); emoções (love, hate, like, care, etc.) verbos de opiniões e crenças (think, believe, know, etc.); existência de uma situação (deserve, fit, matter, reflect, etc.), entre outros. Uma vez que esses verbos refletem estados em inglês, sem desenvolvimento no tempo, são tratados de uma maneira distinta dos verbos de ação que envolvem progressão ou mudança.

Além desses verbos de estado inerente e os de ação, existe a possibilidade da repetição constante ou regular de uma ação, o que cria um hábito duradouro, que existe ou não, ou seja, ações habituais podem ser tratadas como estados ou como ações que os compõem.

I go to work every day.

I study English.

Os verbos work e study envolvem ações cuja prática regular cria uma situação percebida como permanente e duradoura. Uma vez que o tratamento gramatical reflete a natureza da situação (estado ou ação), ações habituais podem, dependendo da situação e do enfoque do falante, ser tratadas como qualquer um.

Voltemos ao nosso gráfico, que contém quatro alternativas. A primeira, Existência, é uma forma mais neutra de fazer referência à situação. Em princípio, essa referência pode ser a estados/hábitos/ações presentes (com o present tense) ou passados (com o past tense), mas, na realidade, é rara a menção a uma ação que não inclua também uma referência à sua duração / natureza temporária. (Existe o caso do narrador de um jogo de futebol que fala, "X passa para o direito, chuta,...." porque, nesse caso, o que importa é o fato de a ação existir; que é vista como um elemento momentâneo). São principalmente estados e hábitos os que ocorrem com verbos no presente.

Em relação a situações passadas, o falante tem a opção de fazer referência à existência passada de estados e hábitos, mas também de ações. Assim, temos John had a cat (estado), John studied English every day (hábito) e John kicked the ball over the goal line (ação).

\section{REFERÊNCIA AO TEMPO EM INGLÊS}

A grande divisão dos tempos verbais em inglês não envolve a questão de tempo em si, mas a maneira pela qual a situação é encarada. Entretanto, em cada uma das quatro divisões aspectuais existe uma subdivisão relacionada com a questão do tempo (presente ou distanciado do presente). 
Trab.Ling.Aplic., Campinas, 44(2) - Jul./Dez. 2005

Em relação a situações mostrando existência presente, temos os seguinte exemplos:

The sky is blue.

John likes ice cream.

Mary lives in a large city.

Peter works at the university.

O primeiro exemplo traz um estado - o céu é azul. Não há menção da duração desse estado, mas somente a afirmação de que, no momento, existe. A mesma coisa para o segundo, que afirma que, no momento, John gosta de sorvete. Não sabemos (nem estamos preocupados) se sempre gostou ou se a situação é de cunho recente. A terceira situação está relacionada à residência em algum lugar, que também existe ou não, ou seja, também se refere a um estado.

O quarto exemplo representa um hábito: Peter trabalha na universidade. É uma situação habitual que se repete todos os dias. Não significa que passa o tempo todo no trabalho, mas em vez disso, que repete diariamente a ação de trabalhar.

Em todos esses exemplos, a ênfase está na existência da situação (estado ou hábito) no momento presente. É a existência que é relevante e não a sua duração.

A outra grande subdivisão em relação a tempo se refere a estados ou ações distanciados do presente. O mais comum é distanciamento em relação ao tempo, i.e., situações no passado. Esse distanciamento pode, então, ser cronológico, envolvendo ações, hábitos e estados, como nos exemplos abaixo:

5) The sky was blue (quando se formou a terra).

6) John liked ice cream (quando era criança).

7) Mary lived in a large city (em outra época, não agora).

8) Peter worked at the university (no ano passado, porque agora faz outra coisa).

9) The player kicked the ball into the net to make a goal (a ação começou e terminou no passado).

Mas, existem outros tipos de distanciamento; nos seguintes exemplos, o distanciamento é social, de polidez. Assim, numa mesma situação, é mais polido perguntar 10) do que 11) ou de pedir 12) do que 13)

10) What was your name?

11) What is your name?

12) Could you pass the salt?

13) Can you pass the salt?

Um terceiro tipo de distanciamento envolve distanciamento da realidade ou a expressão de uma situação dúbia ou incerta como em 14) e 15) abaixo. 
14) Would you mind if I was late on Monday (segunda-feira ainda não chegou é não é certo que vou atrasar).

15) If I had gone, I would have seen him (Eu não fui e então não o vi).

Em todas essas situações, usa-se o past tense, que serve tanto para falar de ações ou estados no passado, quanto para fazer pedidos gentis ou falar de suposições hipotéticas.

\section{FREQÜÊNCIA NO USO DOS TEMPOS VERBAIS SIMPLES}

Esses dois tempos verbais (simple past tense e simple present tense compõem a grande maioria dos verbos em textos em inglês, independentemente do tipo de texto. Biber et al. $(1999)^{2}$ relatam uma série de estatísticas (número de palavras por milhão de palavras no corpus) bastante esclarecedoras sobre o uso desses (e outros) tempos verbais em inglês. Apontam que em torno de $90 \%$ dos verbos em inglês aparecem nesses tempos simple, com o mínimo de $85 \%$ nos noticiários e de $93 \%$ em textos acadêmicos... Os tempos presentes são bem mais freqüentes nos textos em geral do que os no passado (quase o dobro: 274.282 e 152.379 palavras, respectivamente), sendo que na ficção o past tense predomina (56\%), enquanto na conversação e no texto acadêmico é o present tense $(78.4 \%$ e $77.4 \%$, respectivamente). Na conversação, são usados mais de 100.000 verbos por milhão de palavras em tempo verbal present, com menos de um terço desse número no past (aproximadamente 28.000), enquanto na ficção são aproximadamente 70.000 verbos no past e somente uns 55.000 no present. Textos acadêmicos têm, em geral, menos verbos (60\%) do que na conversação (78.700 vs 129.522 palavras, respectivamente).

Apesar da predominância dos verbos nos tempos simples afirmando existência (seja existência atual, seja distante do atual), questões de ordem gramatical exigem, em certas situações, o emprego dos dois aspectos no quadro, de ações em progresso e de estados delimitados, Os estados delimitados (perfect tenses) são ligeiramente mais freqüentes do que os progressivos na análise de corpus de Biber et al., cada um correspondendo a entre 5 a $10 \%$ dos verbos, mas com a frequiência variando em função do tipo de texto. Assim, os perfects são mais frequientes nos noticiários (mais que 13\% dos verbos), mas somente 5\% na conversação. Também há diferenças entre inglês britânico e inglês americano, com a versão britânica, especialmente os noticiários, apresentando mais perfects, enquanto que, nas conversações no inglês americano, há maior número de progressives.

\footnotetext{
${ }^{2}$ Baseado no seu estudo do uso da língua inglesa num corpus de mais que 40 milhões de palavras, Biber et al. (1999) apresentam dados sobre 4 tipos básicos de textos: conversação (oral e informal), ficção (escrito, basicamente narrativa sobre eventos imaginários para finalidades estéticas e recreativas), noticiários (escrito, com foco informativo) e textos acadêmicos (também escritos, mas bastante formais). Apresentam os dados em forma de histogramas, mas uma régua e um pouco de interpolação levam a informações mais específicas das quantidades sobre a ocorrência de formas e significados dos mais variados.
} 


\section{ASPECTOS GRAMATICALIZADOS EM INGLÊS}

Como mencionado acima, o que é relevante em relação ao aspecto para o sistema verbal em inglês se distingue do português. Estão envolvidos dois sistemas distintos, os sistemas 1 (durativo) e 3 (estativo) de Friedrich, e é essa diferença a que traz sofrimento e confusão para os aprendizes brasileiros, que precisam aprender a fazer distinções que não fazem na língua materna.

Aspecto progressive Os progressivos apresentam ações vistas como em progresso e, por isso, temporárias. Em relação a ações passadas, o past progressive equivale a certos usos do pretérito imperfeito do português, mas a chave é a questão de ações — ações em progresso independentemente de a situação ser passada ou presente - em contraste com estados / hábitos que simplesmente existem.

John was studying.

John estudava/estava estudando/vinha estudando.

Em português, é possível, se assim se quiser, dar maior ênfase ao aspecto de progressão e temporariedade ao usar uma locução verbal (estar ou vir, com o gerúndio), mas, em inglês, a distinção é obrigatória. Por outro lado, o seu uso não traz nenhum destaque para esse aspecto. Para ações presentes (como John is studying a lot these days), o português também oferece opções: John estuda / está estudando / vem estudando muito esses dias.

Aspecto perfect. Os tempos verbais progressive diferem pouco das formas de português, com o problema principal advindo das diferenças no aspecto lexical (os verbos vistos como estado em inglês). São os perfects que se distanciam muito. Como afirmado acima, os perfects são usados para fazer referência a estados delimitados. Vamos olhar um primeiro exemplo.

\section{He has lived in Campinas for a year [vs He lives in Campinas].}

Nesse exemplo, a delimitação é clara (for a year), mas, em português, a delimitação é irrelevante e a oração se refere ao estado atual de morar - então, em português, seria ele mora em Campinas há um ano. É relativamente fácil reconhecer o fato de que esses verbos, lexicalmente referentes a estados, continuam fazendo referência aos mesmos estados no perfect, deixando explícita, entretanto, a delimitação. Existindo tal delimitação, a gramática da língua inglesa exige o uso de um tempo verbal perfect. Se o estado é atual, será um present perfect; se for distanciado cronologicamente do momento atual, seria o past perfect, como no exemplo abaixo:

He had lived in Campinas for 10 years when I met him.

Morava em Campinas há 10 anos quando o conheci. 
Como afirmado acima, a chave para a compreensão de todos os verbos é a questão de estado e isso continua relevante para os Perfect tenses. Fabricius-Hansen (1998) afirma que os tempos perfect constituem/são a maneira de tornar ações em estados. Todos os verbos num perfect tense se referem a estados. Entretanto, o falante não encara esses estados como meramente existentes - eles são deliminados no tempo (com início ou duração delimitados). Fornecem um pano de fundo para ações futuras à situação colocada (Li at al., 1982). Pragmaticamente, servem para apresentar o pano de fundo, o ponto de partido para futuras ações (Hopper, 1982); não servem para afirmar verdades em geral, mas apontam a relevância de um estado em algum momento específico do tempo (presente ou passado) com o estado estendendo-se até (e existindo em) o momento de referência, que é o momento atual para o present perfect e algum momento no passado para o past perfect).

Um estado, tal como possuir ou conhecer, tem, por definição, duração, mas tal duração pode ser implícita (como no present tense) ou destacada e delimitada, como na oração seguinte, na qual a expressão adverbial explicita que o estado de morar atualmente existente dura já há 5 anos (e somente 5 anos)

Ele mora em Campinas há 5 anos.

Como mencionado acima, também existem verbos cujos valores lexicais fazem referência a ações. O problema maior surge com verbos de ação no present perfect, tais como eat, read, lose, etc. Nesses casos, o estado a que se faz referência com o present perfect não corresponde a nenhum estado reconhecido em português. É o estado que surge como resultado de uma ação (em contraste com a ação em si). Como Li et al. afirmam, o perfect pode "envolver uma ação, mas... não fala sobre a ação de ... sair ou comprar, mas sobre o estado de ... ter feito as compras e a relevância desse estado para a situação presente"(1982: p. 25); Assim temos as orações seguintes:

He bought the pen (ação).

He has bought the pen (estado resultante $=$ ter).

Na segunda oração, o estado (resultante) é o que surge a partir da ação de comprar. Nesse caso, o que estabelece o limite desse estado é a ação em si. Assim temos as seguintes orações:

He has lost his keys (está num estado de não ter chaves).

He has eaten the cake (o estado atual é de não ter mais bolo/ talvez que ele esteja satisfeito).

He has read the book (o estado dele é de saber o que existe no livro).

Em cada uma, houve uma ação no passado e, a partir disso, surgiu um estado (que é o enfoque da frase). 
Trab.Ling.Aplic., Campinas, 44(2) - Jul./Dez. 2005

Não há mesmo nada equivalente em português. A questão de estado é irrelevante para o português, como também a questão de limites. Na falta de uma opção para fazer referência a tais estados, geralmente se fala da ação, só que a ação também pode ser enfocada em inglês.

Assim, ele comprou o livro equivale a He bought the book e não a He has bought the book. Esta última faz referência ao estado atual de posse do livro, um estado que surgiu a partir da ação da compra - alguma coisa do tipo Ele está com o livro depois que comprou.

Dada a impossibilidade de discernir equivalência com o que se fala em português, nessas situações existe uma certa tendência de usar o advérbio já para tentar enfatizar que a compra se completou. E é verdade que, para ter resultados (a posse), a ação está necessariamente terminada, mas esta solução não é muito feliz porque, pragmaticamente, o uso do present perfect traz uma ênfase para a atualidade - é agora, depois de tanto tempo, que existe o estado (que pode ser percebido como pouco ou muito). Dá uma forte ênfase no "agora", enquanto falar de um estado no present tense afirma a existência desse mesmo estado, mas de uma forma mais neutra.

Voltemos, agora, para o nosso exemplo da compra do livro. Quando se diz he has bought the book, a informação em destaque é que agora ele está com o livro; como pano de fundo, inclui informação de que tal estado atual existe desde a compra. Esta informação pode fortalecer a duração de um tempo longo ou curto.

He has had the book for ages.

He has just bought had the book.

O importante não é a duração do estado atual, mas o fato de que, nesse momento, o estado existe. É uma maneira de realçar a sua existência atual.

Pragmática do uso do present perfect. O que leva ao uso do present perfect na revisão bibliográfica de artigos científicos é o desejo do autor de dar realce à importância de certos resultados de pesquisa. O uso do perfect destaca as referências com mais relevância no âmbito da pesquisa em andamento, sendo relatada; os resultados dessa pesquisa têm relevância atual, colocando em segundo plano as referências com menos relevância: simplesmente aconteceu uma investigação no passado. É a diferença entre dizer que cientistas, no início do século passado, fizeram uma certa experiência e afirmar que, agora, sabemos uma coisa devido ao trabalho dos cientistas no início do século passado.

In the early 1900s scientists discovered that X [ênfase na ação dos cientistas].

Scientists have discovered that X [ênfase no fato que agora sabemos].

A mesma função do present perfect de realçar o que é importante no momento da fala também explica o seu uso nas manchetes. A situação ou estado atual é de suma importância no relato das coisas em andamento no mundo - quando algo chega a ser considerado notícia, envolve um estado relevante (e normalmente novo). Assim, temos Brazil has won 
several medals during these Olympic games (manchete logo depois da conquista de uma dessas medalhas, destacando a situação do Brasil como vencedor), mas também Brazil won several medals during the Olympic games (comentário em artigo sobre o desempenho do Brasil no esporte em nível mundial).

A mesma situação do present perfect se repete com o past perfect. Esse tempo verbal coloca a situação existente num momento explícito no passado:

By 1960, scientists had discovered $\mathrm{x}$.

When he came, I had finished eating.

Enquanto em português, o uso do mais-que-perfeito realça ações anteriores a outras ações, o past perfect apresenta estados que eram atuais num dado momento no passado. A ação em si seria expressa no simple past.

After he read the book, John came.

He read the book before John came.

O uso das expressões before e after deixa clara a seqüência cronológica dos eventos. Mas com o perfect, é realçado o estado existente, num momento identificado como sendo antes de agora.

Pragmática do uso do past perfect. Numa narrativa, o efeito desse uso do past perfect (colocar a situação que reina num momento específico) tem o efeito de fornecer informações de pano de fundo para a progressão das ações principais da estória. Freqüentemente, explicita os eventos e acontecimentos que levaram aos eventos focados na narrativa, um modo de estabelecer do pano de fundo para as ações da narrativa. Uma vez que isso é a função do pretérito imperfeito em português, que distingue entre eventos destacados (no pretérito do perfeito) das informações de pano de fundo (no pretérito imperfeito), a tradução mais adequada do past perfect é freqüentemente o pretérito imperfeito e não alguma forma do mais-que-perfeito.

\section{OS PERFECT PROGRESSIVES COMBINANDO OS DOIS ASPECTOS}

O nosso gráfico mostra que, em inglês, os dois aspectos obrigatórios, além de serem diferentes do aspecto gramaticalizado em português, podem ser percebidos como simultaneamente relevantes (ver o último quadrado do gráfico). Essa dupla aspectualidade combina aspectos de progressão e de estado delimitado. Entretanto, existem duas possibilidades (que dependem do significado lexical do verbo de estado ou ação). A primeira possibilidade envolve a limitação advinda dos perfects com a progressão de ações:

He has been waiting for hours. 
Essa situação difere de he is waiting por limitar a duração da espera. Toda ação em progresso é vista como sem limites; ao se colocar um limite explícito, torna-se necessário o uso de um tempo verbal perfect:

He had been studying since noon.

Esse exemplo equivale a he was studying, só que, uma vez que se inclui o limite since noon, é exigido o uso de um tempo verbal do perfect, no caso, o past perfect.

De novo, os problemas enfrentados são maiores com os verbos de ação que se tornam estados resultantes do que com o uso do perfect. Assim, he has been buying pens, sem expressão adverbial explicitando a limitação de uma série de ações, não se refere a uma ação temporária em progressão (he is buying pens, que equivaleria a ele está comprando canetas), mas a uma série de resultados (uma progressão de estados). He has been buying pens implica na posse de um número cada vez maior de canetas: ele tinha uma como resultado da primeira compra, mais uma depois da segunda compra, e assim por adiante. Difere de he has bought some pens, entretanto, porque enfoca a progressão de posses e não uma posse final, cumulativa.

\section{CONSIDERAÇÕES FINAIS}

Voltando ao quadro dos aspectos em inglês, o falante poderia interpretar uma mesma situação de quatro maneiras diferentes e a distinção é obrigatoriamente refletida na sintaxe através da escolha verbal. Mas, ao mesmo tempo, traços semânticos dos verbos (de ação e estado) são relevantes nessas interpretações.

Como visto aqui, a questão de aspecto em inglês é complexa para brasileiros, porque, além de ser diferente do que se faz na língua materna, envolve a interpretação do falante em relação à situação. Uma mesma situação pode ser vista de maneiras diferentes.

Podemos dar o seguinte exemplo, mostrando como uma mesma situação de referência pode ser vista de várias maneiras e como o ponto de vista fica explícito através do tempo do verbo. O exemplo (study) freqüentemente se refere a um hábito (um tipo de estado), mas tais verbos, fazendo referência a hábitos, podem também ser vistos como ações (os incidentes individuais que compõem o hábito).

He studies English.

He is studying English

He has studied English since he was a child.

He has been studying English since he was a child.

O primeiro exemplo se refere ao hábito de estudar inglês, ilimitado, não a uma instância específica, nem à atividade atual com duração explícita. Afirma que o rapaz costuma estudar. O segundo exemplo enfatiza a natureza repetitiva das ações envolvidas no estudo do inglês 
e deixa claro o envolvimento atual no processo de estudar. O terceiro e quarto exemplos incluem informações explícitas sobre a duração das ações em progresso, forçando, assim, a passagem dos tempos verbais para o perfect: no caso do terceiro, o present perfect $\mathrm{e}$, no quarto, o present perfect progressive. Assim, no terceiro, temos a mesma idéia do primeiro, só que de maneira mais atual, limitada, e, no quarto, temos a ênfase no processo atual, porém, limitado.

Além disso, existe outra possibilidade:

He has studied English.

Sem a expressão adverbial explicitando o limite, mas com o uso do present perfect, a situação é interpretada de uma maneira diferente, como o resultado da ação de estudar ele não estuda mais, mas está com a informação que veio a partir do estudo. Uma vez que a escolha depende da interpretação do falante, não necessariamente de traços inerentes ao verbo e à situação, é necessário compreender os elementos contextuais que estão envolvidos para conseguir utilizá-los no emprego dos verbos.

\section{REFERÊNCIAS BIBLIOGRÁFICAS}

ALMEIDA, J. de. (1978). Introdução ao estudo das perífrases verbais de infinitivo. Assis: ILHPA-Hucitec.

COMRIE, B. (1976). Aspect. London: Cambridge University Press, 1976.

COSTA, S. B. B. (1997). O Aspecto em Português. São Paulo: Editora Contexto.

EL-DASH, L. G. (2005). "State verbs in English: Pragmatic and syntactic implications. Contexturas: Ensino Crítico de Língua Inglesa 8: 41-54.

FABRICIUS-HANSEN, C. (1998). “Tense and time, Pragmatics of”. In J. Mey (org.) Concise Encyclopedia of Pragmatics. Amsterdam: Elsevier, p. 1000-1001.

HOPPER, P. (1982). “Introduction”. In P. Hopper (org.) Tense-Aspect: Between Semantics and Pragmatics. Amsterdam: John Benjamins, p. 3-18.

LI, C. N., THOMPSON, S. A, e THOMPSON, R. M. (1982). "The discourse motivation for the perfect aspect: The Mandarin particle li." In P. Hopper (org.) Tense-Aspect: Between Semantics and Pragmatics. Amsterdam: John Benjamins, p. 19-44.

RAFFERTY, E. (1982). “Aspect in Indonesian”. In P. Hopper. Tense-Aspect: Between Semantics and Pragmatics. Amsterdam: John Benjamins, p. 3-18. 